\title{
Fetal upper mediastinum - normal and abnormal findings in obstetric ultrasound screening
}

\author{
Anna Wojtowicz@, Hubert Huras® \\ Department of Obstetrics and Perinatology, Jagiellonian University Medical College, Cracow, Poland
}

\begin{abstract}
Fetal cardiac assessment is an integral part of the obstetric ultrasound. The inclusion of the outflow tracts and the three-vessel and tracheal view into the ultrasound screening enhances the detection rate for cardiovascular anomalies. Both, international and Polish guidelines recommend routine evaluation of the upper mediastinum. The aim of the study was to present the principles for assessing the structures of the upper mediastinum in normal conditions and to draw attention to the pathologies which may be visible in this plane.
\end{abstract}

Key words: upper mediastinum; three-vessel view; three-vessel and tracheal view; heart defects

Ginekologia Polska 2020; 91, 10: 620-628

\section{INTRODUCTION}

Fetal cardiac assessment is an integral part of the obstetric ultrasound. In the early 1980s, the four-chamber view for congenital heart defects (CHD) screening was introduced [1, 2]. The early studies indicated an $80-87 \%$ sensitivity of this view for the detection of fetal heart defects [2,3]. However, in the subsequent years, it turned out that single ventricle heart defects can be detected in the four-chamber view, but anomalies involving the outflow tracts and the great vessels may remain undetected [4, 5], and the sensitivity of the four-chamber view was re-estimated to be $30-60 \%$ [3-7]. In almost 70\% of cases of the conotruncal anomalies, the four-chamber view is normal or almost normal $[4,9,10]$. The defects like tetralogy of Fallot (ToF), double outlet right ventricle (DORV), anomalies of the aortic arch, stenosis of the semilunar valves, common arterial trunk (CAT), and transposition of the great arteries (TGA) may have a normal four-chamber view but not the upper mediastinum view. Yoo et al. [10], proposed a three-vessel view (3VV) in the transverse plane of the fetal upper mediastinum as a simple way to detect anomalies of the ventricular outflow tracts and the great vessels. However, in this section the aortic arch cannot be assessed, which is also challenging in the classic long-axis view. In 1992, Achiron et al. [11], proposed a concept of the extended fetal echocardiogram, and recommended to incorporate the outflow tracts and the three-vessel and tracheal view (3VT) into screening for fetal cardiac defects [12]. A 3VT view enables to assess the anatomy of the great vessels in the mediastinum and, which is especially noteworthy, provides information about the aortic arch, its width, and its location in relation to the trachea. The inclusion of the $3 \mathrm{VV}$ and the 3VT view into the screening has led to increased sensitivity in detecting several congenital heart defects [10,13-15]. In one prospective study, $70.8 \%$ of $C H D$ cases presented at least one abnormality in 3VV and 3VT [15].

International ultrasound organizations such as the International Society of Ultrasound in Obstetrics and Gynecology (ISUOG) [16], and the American Heart Association [17], recommended to incorporate the upper mediastinum assessment in cardiac screening in order to detect anomalies of the outflow tracts and the great vessels. In Poland, the 2009 recommendations [18] as well as the 2012 and the 2015 guidelines of the Polish Society of Gynecologists and Obstetricians [10, 20], also include routine assessment of the vessels in the upper mediastinum during ultrasound examination. Hence, the aim of this study was to present the principles for assessing the structures of the upper mediastinum in normal conditions and to draw attention to the pathologies which may be visible in this section.

\section{ANATOMY OF THE UPPER MEDIASTINUM}

Starting from the four-chamber view and moving slightly cephalad, the outflow tracts are visible, followed by the structures of the upper mediastinum, with the image of the three vessels (three-vessel view, 3VV) (Fig. 1). In this section, 


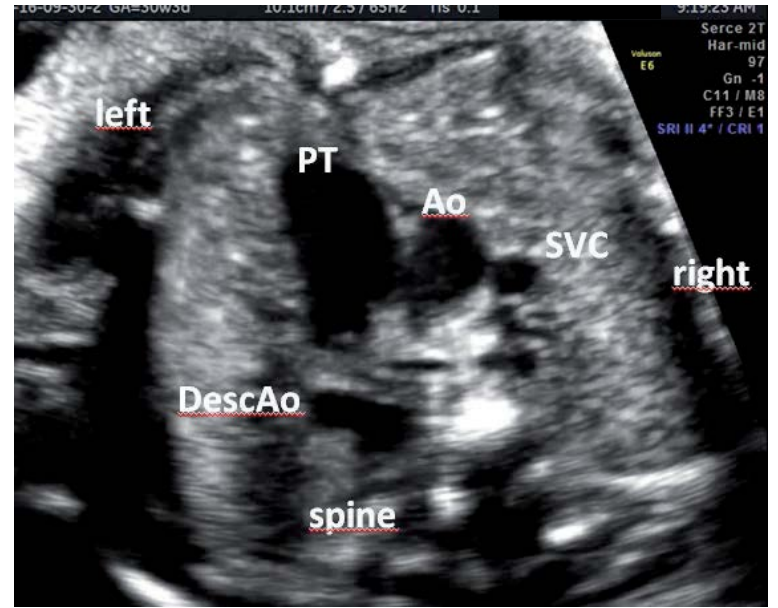

Figure 1. Three-vessel view: going from the anterior and left to the right and posterior side, the oblique cross-section of the pulmonary trunk, the transverse section of the ascending aorta and the superior vena cava can be seen; Ao - aorta; DescAo — descending aorta; PT - pulmonary trunk; SVC — superior vena cava

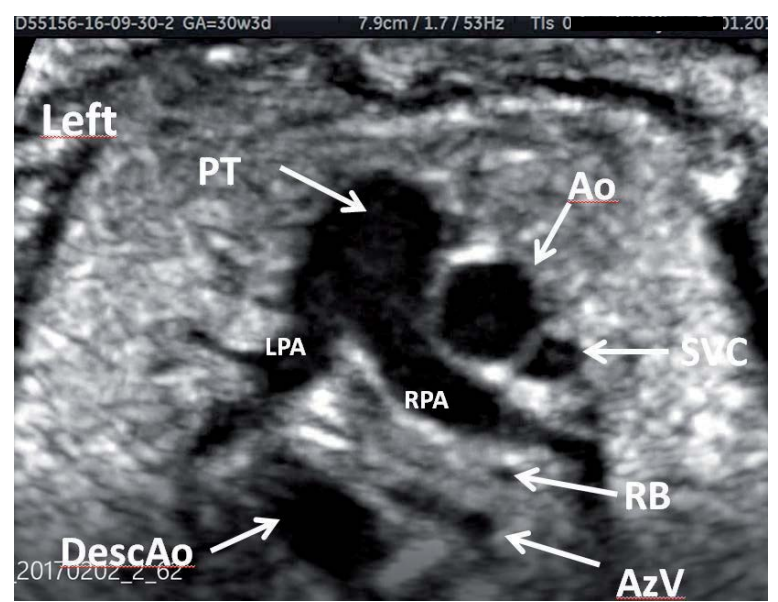

Figure 2. Branching of the pulmonary trunk to the left and right pulmonary arteries; Ao - aorta; AzV — azygos vein; DescAo — descending aorta; LPA — left pulmonary artery; PT — pulmonary trunk; RB — right bronchi; RPA — right pulmonary artery; SVC - superior vena cava

going from the anterior and left to the right and posterior side, the oblique cross-section of the pulmonary trunk, the transverse section of the ascending aorta and the right superior vena cava (SVC) can be seen. Under normal conditions, the pulmonary trunk is slightly wider than the aorta, while the aorta is wider than the superior vena cava. The $3 \mathrm{VV}$ also contains the cross-section of the descending aorta, which lies anterior and to the left of the spine. By gentle movement of the probe, it is possible to visualize the connection of the pulmonary trunk through the ductus arteriosus (DA) with the descending aorta as well as the branching of the pulmonary trunk to the left and right pulmonary arteries (Fig. 2). The right pulmonary artery goes straight to the

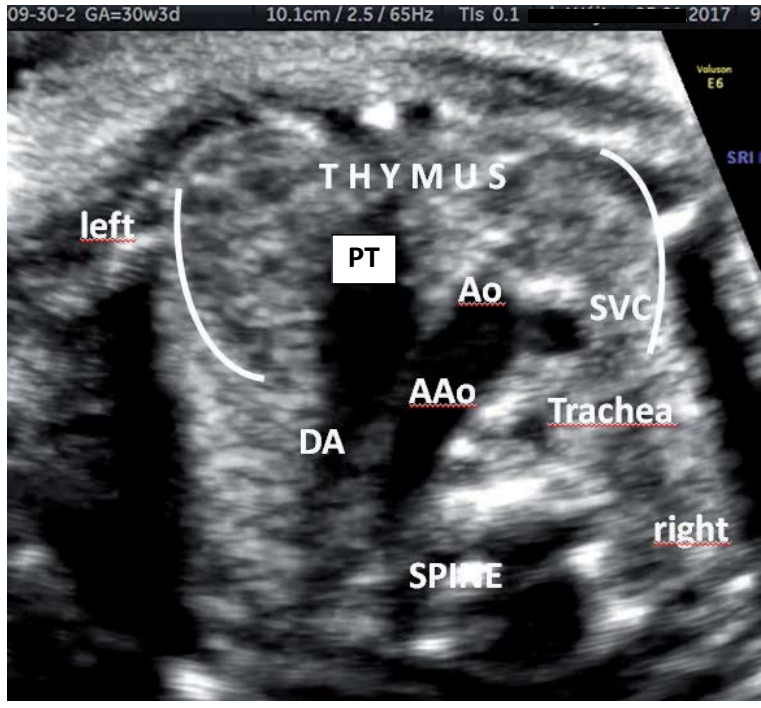

Figure 3. Three-vessel and tracheal view. The aortic arch and ductus arteriosus are running to the left of the trachea; left aortic arch; Ao - aorta; AAo - aortic arch; DA — ductus arteriosus; PT - pulmonary trunk; SVC — superior vena cava

right behind the descending aorta and the superior vena cava, while the left pulmonary artery runs to the left of and posterior to the aorta. At this level, the aortic and the ductal arches cannot be assessed. Only a small cephalad movement allows to visualize the aortic and the ductal arches as well as the localization of these vessels in relation to the trachea (Fig. 3). This plane is called the three-vessel and tracheal view (3VT). Normally, the large vessels in the upper mediastinum are arranged in a $V$ shape directed to the left of the trachea and anterior to the spine. The left arm is formed by the pulmonary trunk that passes into DA and the right arm by the transverse part of the aortic arch, with the isthmus located to the left of the trachea [21]. To the right and more backward in relation to these vessels, a cross section of the superior vena cava, to which the azygous vein drains (often referred to as the'azygous vein arch'), are seen (Fig. 4). The main advantage of this cross-section is the fact that the aortic and the ductal arches are visible together in any axial plane of the upper mediastinum, whereas the longitudinal demonstration of these arches is often limited and difficult to obtain.

In addition, the great vessels, i.e. the pulmonary trunk and the aorta, should not adhere to the anterior wall of the chest. Under normal conditions, going from the front of the chest to the back, the tissue which differs slightly from the lung tissue and which corresponds to the thymus, should be seen (Fig. 3, 4). Usually, the thymus has the same or less echogenicity as the lungs and contains hyperechogenic foci. However, thymus assessment can be problematic. Although various methods of assessing the presence and the measurements of the thymus have been proposed, 


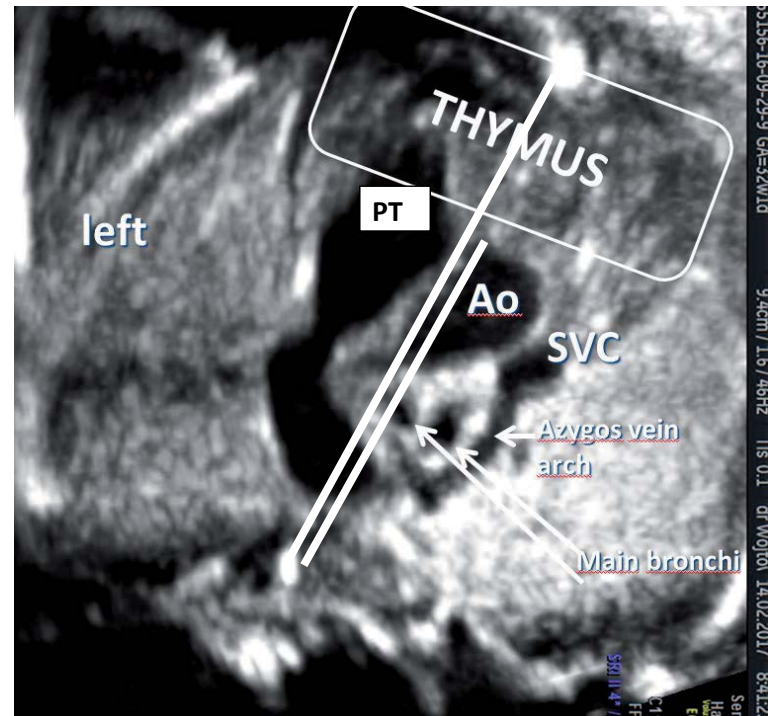

Figure 4. Three-vessel view with the azygous vein draining to the superior vena cava: azygos vein arch; Ao - aorta; AAo - aortic arch; DA - ductus arteriosus; PT — pulmonary trunk; SVC — superior vena cava

none could be described as the gold standard. The use of the internal mammary arteries, which are visible while using color Doppler ultrasonography with a low pulse repetition frequency on both sides of the thymus, has been proposed. These vessels, together with the ductal and the aortic arch on the posterior side and the sternum on the ventral side, form the so-called'thy-box' [22] (Fig. 5). The'thy-box' can be displayed in the fetus from the first to the third trimester of pregnancy. In turn, the size of the thymus can be assessed by measuring the transverse diameter, which increases with the advancement of the pregnancy, from an average of $12 \mathrm{~mm}$ at 19 weeks to $40 \mathrm{~mm}$ at 38 weeks of gestation [23]. The thymus diameter shows accelerated growth during pregnancy, with the diameter in millimeters being smaller than the gestational week in second and early third trimester, equal to the gestational age in weeks at 33 weeks, and larger later in pregnancy. During the second trimester, the thymus diameter in millimeters is equal to the abdomen circumference in centimeters. Another method of assessing the presence of the thymus and its size is calculation of the so called fetal thymic-thoracic ratio (TT-ratio), i.e. the ratio of the anteroposterior thymus diameter to the intrathoracic mediastinal diameter measured in the 3VT view (Fig. 4) [24]. In a study by Chaoui et al. [24], the TT-ratio did not show any statistically significant change during gestation, with a mean value of 0.44 . It was observed that in more than $90 \%$ of fetuses with the $22 q 11$ deletion the TT-ratio was < 0.3 [24].

More cephalad in the neighborhood with the posterior wall of the thymus and the anterior border of the aortic arch, the innominate or left brachiocephalic vein (LBCV) is seen.

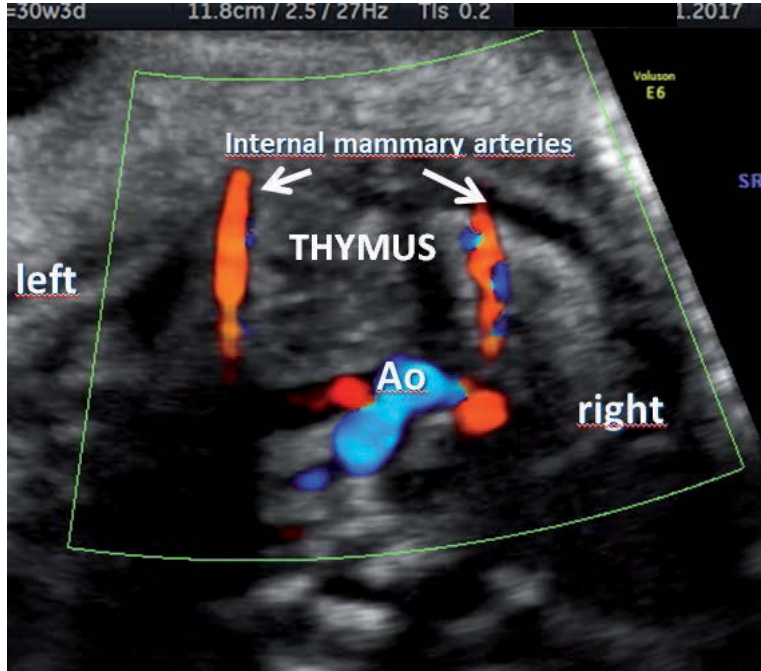

Figure 5. „Thy-box": thymus visible between internal mammary arteries on both sides; Ao - aorta

LBCV is formed by the confluence of the left jugular and left subclavian veins, and drains into the right superior vena cava [25]. A dilatation of LBCV was noticed in the supracardiac type of total anomalous pulmonary venous confluence and in the vein of Galen aneurysm [25]. Moreover, the absence of LBCV was observed in cases with a persistent left superior vena cava (LSVC) with a right superior vena cava (RSVC) [25].

Color Doppler assessment is a valuable supplement to the 2-dimensional ultrasound. Under normal conditions, the use of the color Doppler option allows the pulmonary trunk and the aorta to fill in one color, which means the flow is from the heart, giving the image of a'blue V-sign'(Fig. 6A) or a'red V-sign' (Fig. 6B), depending on the color marking the setting. This flow is laminar and additionally shows the shape of the vessels. Thus, the use of color Doppler improves the visualization of the vessels. In some conditions, blood flow in the vessels is more visible than the vessels themselves in $2 \mathrm{D}$ imaging, as is the case in women with obesity or in cases of unfavorable fetal position. The use of color Doppler confirms the presence of the pulmonary trunk and the aorta allowing to assess their shape, width, and direction of the blood flow, which is particularly valuable in detecting ductus arteriosus depending flow (retrograde flow). Color Doppler modality in a more cranial plane to the 3VT plane allows to visualize the aortic arch branches with the right subclavian artery course [26]. The right subclavian artery extends from the brachiocephalic trunk and is visible with color Doppler modality as a vessel running to the front and right to the trachea (Fig. 7).

Due to the high resolution of the probes, apart from the vascular structures in the upper mediastinum, it is also possible to visualize the esophagus behind the trachea and the trachea can be seen to its bifurcation (Fig. 4). 

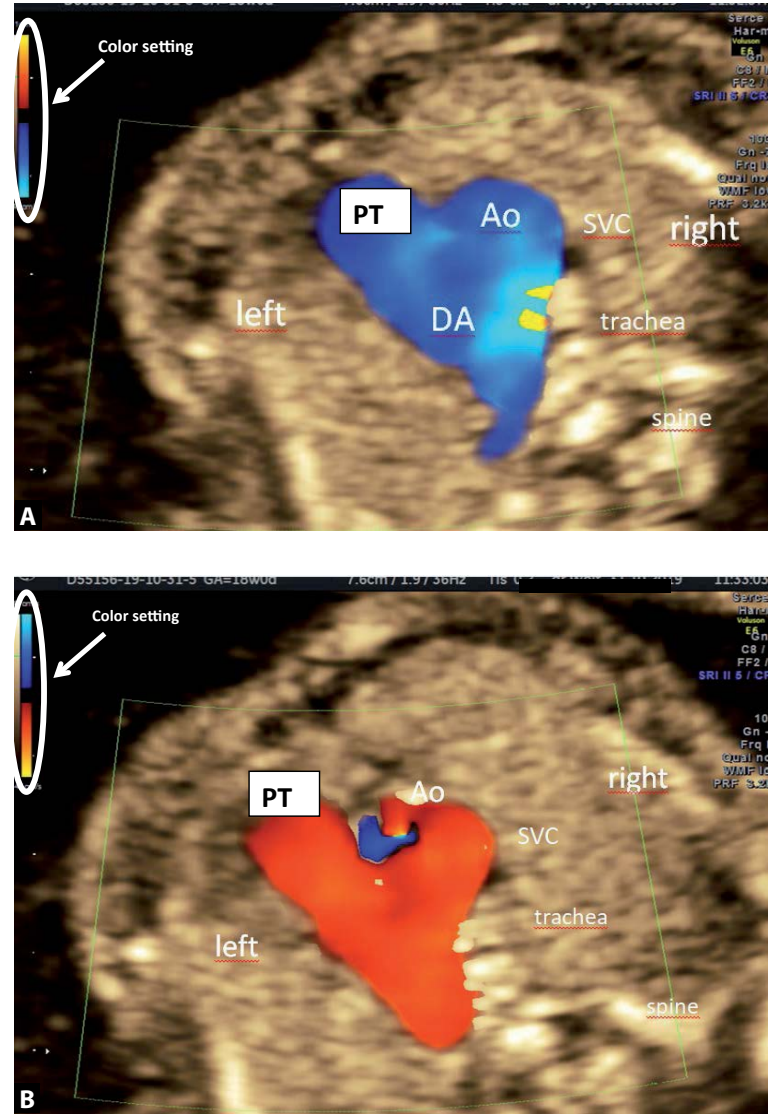

Figure 6. Color Doppler of the three-vessel and tracheal view depending on the setting; A. "blue V-sign" - color Doppler showed blood flow from the probe in blue; B. "red V-sign" - color Doppler showed blood flow from the probe in red; Ao - aorta; DA — ductus arteriosus; PT — pulmonary trunk; SVC — superior vena cava

\section{Abnormalities Detected In The Upper Mediastinum}

When assessing the upper mediastinum, the number of visible vessels, their size, shape, arrangement and alignment should always be determined [10]. In addition, attention should be paid to the possibility of pathological connections between the vessels, to the position of the transverse part of the aortic arch in relation to the trachea, and to the nature of the blood flow in the great vessels using color Doppler. It is also possible to assess pulmonary branching, ductus arteriosus width and the presence/absence of the thymus.

\section{Abnormal number of vessels}

An abnormal number of vessels may affect the arterial or the venous vessels, for example the presence of four instead of three vessels, as in the case of LSVC, which is located to the left of the pulmonary trunk (Fig. 8A). LSVC usually drains to the coronary sinus, which is dilated and visible in the left atrium at the four-chamber view. LSVC may be isolated or may be associated with hypoplasia of the left-sided structures, such as coarctation of the aorta

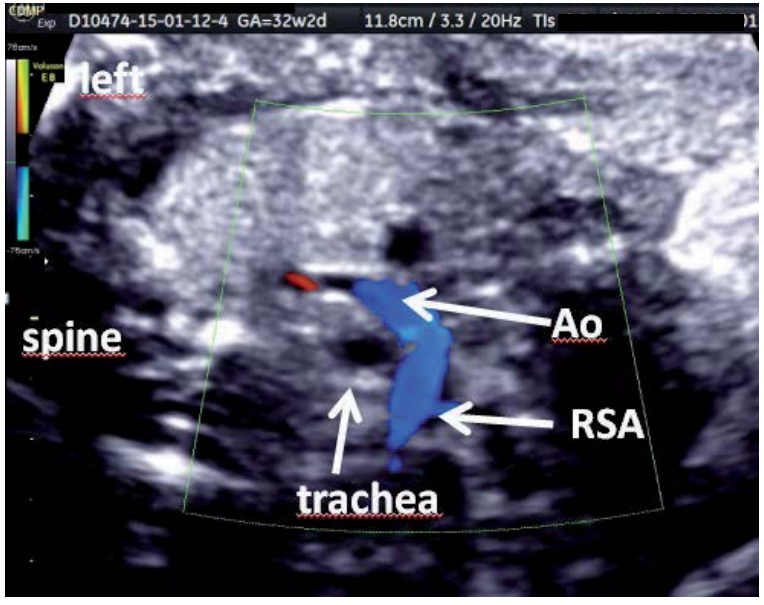

Figure 7. Right subclavian artery running to the front and right to the trachea; Ao - aorta; RSA — right subclavian artery

(Fig. 8A). In cases where LSVC and right SVC are persistent, the left brachiocephalic vein cannot usually be seen [25]. The diagnosis of persistent LSVC with the absent right SVC is a rarer and challenging condition. In such cases, three vessels, but going from the left to the right LSVC, the pulmonary artery and the aorta can be seen (Fig. 8B).

An abnormal number of vessels in the upper mediastinum, usually one large arterial vessel and the superior vena cava, is often found in complex heart defects, e.g. in case of TGA, DORV or ToF. In these cases, the two great vessels come out of the heart, but due to an abnormal arrangement or alignment of the outflow tracts, only one arterial and one venous vessel are observed in the upper mediastinum. Typically, the large arterial vessel in question is the aorta (Fig. 9), or the pulmonary artery with continuation in the ductal arch, while the aorta is hypoplastic and only visible when imaging with color Doppler, as in the case of hypoplastic left heart syndrome. A real anomaly in vessel numbers occurs in cases with a single arterial vessel coming out of the heart such as the CAT, or ToF with pulmonary atresia and an absent duct.

\section{Abnormal vessel size}

One of the vessels may be hypoplastic or dilated. Dilatation of one artery may be found in cases of stenosis of the semilunar valve as a post-stenotic dilatation of the artery. Dilatation of the aorta is seen in fetuses with Marfan syndrome and aneurysm of the ascending aorta [27] (Fig. 10A, 10B). In cases with ToF with absent pulmonary valve, a huge dilatation of the pulmonary trunk and pulmonary arteries with absent ductus arteriosus are observed. Also, the right SVC may be dilated due to increased blood flow from the azygos vein, which is visible in the rupture of the inferior vena cava with vena cava azygos continuation in cases of left isomerism or in supracardiac total anomalous pulmonary venous return or in the cases of vein of Galen aneurysm [14]. 

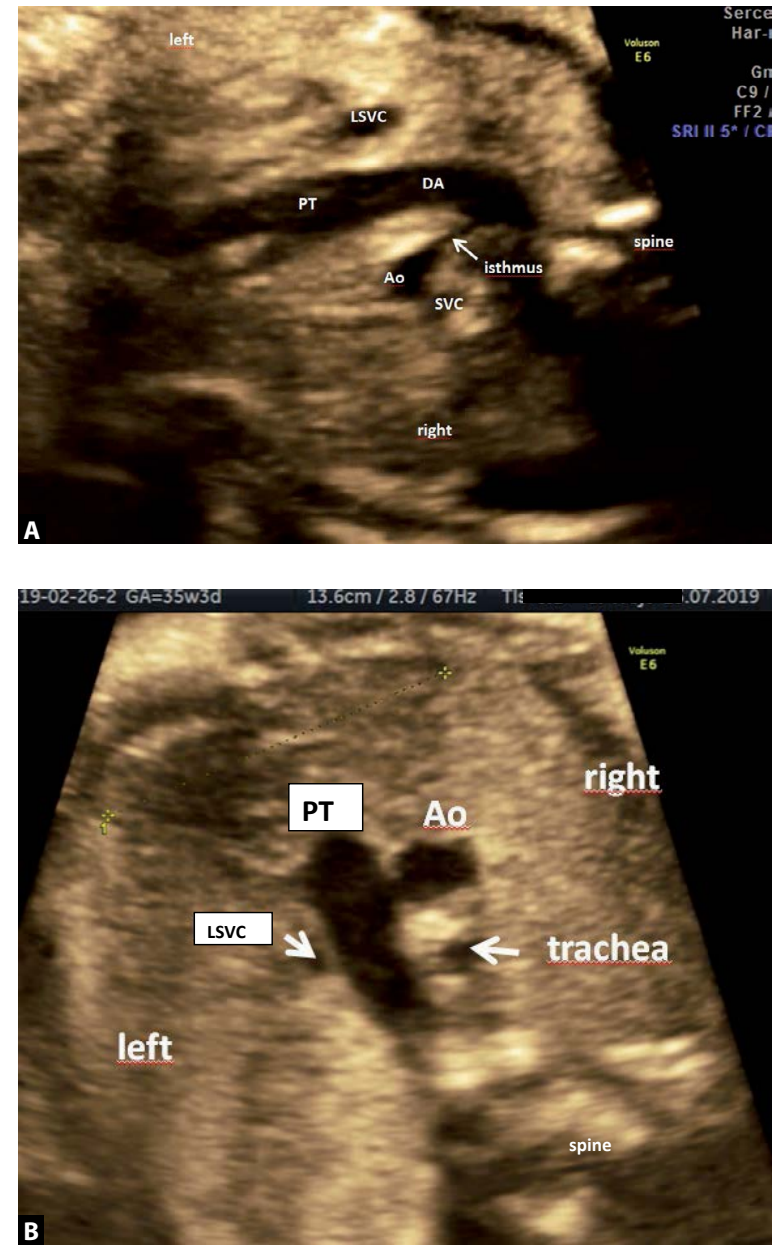

Figure 8. Persistent left superior vena cava (LSVC); A. LSVC located to the left of the pulmonary trunk with right superior vena cava located to the right of the aorta in a case of coarctation of the aorta; B. LSVC located to the left of the pulmonary trunk with absent right superior vena cava; Ao - aorta; LSVC — left superior vena cava; PT - pulmonary trunk; SVC — superior vena cava

Hypoplasia of the aorta with antegrade flow indicates aortic coarctation. A retrograde flow through a hypoplastic aortic arch is found in the hypoplastic left heart syndrome (Fig. 11A, 11B). The assessment of the aortic arch in the upper mediastinum is particularly valuable in suspected aortic coarctation. Aortic coarctation may be suspected if the dominance of the right ventricle in the four-chamber view and narrowing of the aortic arch and isthmus in the upper mediastinum with antegrade flow are observed [28]. Stenosis may also affect the pulmonary artery, as is the case in ToF, Ebstein anomaly or DORV.

\section{Abnormal vessel alignment}

Abnormal vessel alignment means that the three vessels are not positioned in a straight line, but the left-to-right order is preserved, most often due to the shifting of the ascending aorta forward, with or without the pulmonary

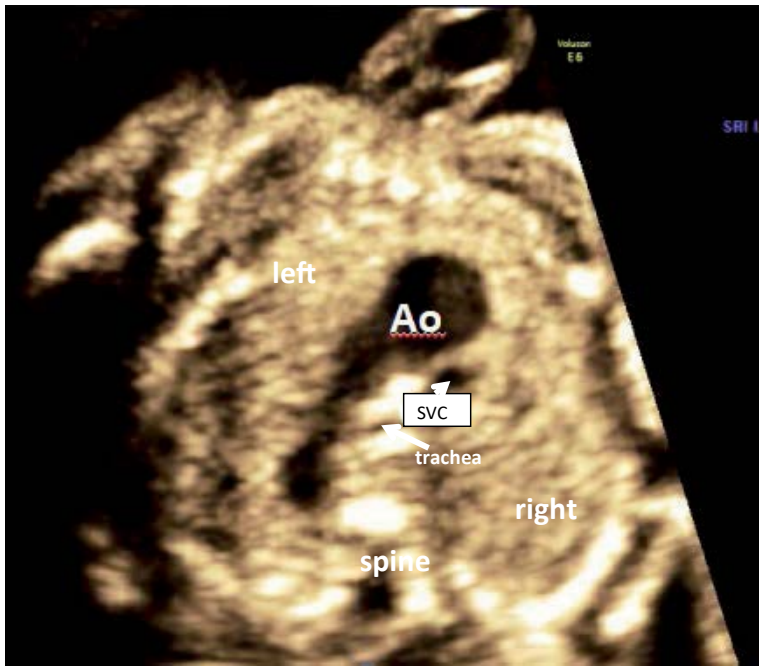

Figure 9. Upper mediastinum in tetralogy of Fallot with two vessels visible: ascending aorta (Ao) and superior vena cava (SVC). In aCGH confirmation of $22 \mathrm{q} 11.2$ deletion. Absent thymus

trunk shifting backwards. It could be seen in cases of perimembranous ventriculoseptal defect with malalignment of the aorta, as is the case in ToF [14]. Abnormal alignment can be observed in DORV (Fig. 12), where the great vessels can be seen side-by side and, less frequently, in transposition. In hypoplastic left heart syndrome and interruption of the aortic arch, the aorta can be shifted backwards. Importantly, abnormal vessel alignment is easier to detect in the three-vessel view than in the 3VT view.

\section{Abnormal vessel arrangement}

Abnormal vessel arrangement, i.e. a complete distortion of the left-right order of the vessels, can be seen in the case of transposition of the great arteries (Fig. 13) as well as in DORV. In those disorders, the vessels are usually arranged in a triangle shape.

\section{Abnormal vessel communications, branching and course}

The upper mediastinum plane allows for the assessment of the aortic and ductal arches and the detection of pathological communications between these vessels, as is the case in the aortopulmonary window (Fig. 14). The communication may extend to the proximal or the distal part or may cover the entire length of the vessels. This defect is often associated with the interruption of the aortic arch.

Moreover, the relation to the trachea of the aortic and ductal arches can be assessed and cases of a right or a double aortic arch can be detected. Initially, during the early stage of embryonic development, a double aortic arch (DAA) is seen [29]. Normally, there is a regression between the rising of the right subclavian artery and the descending aorta 

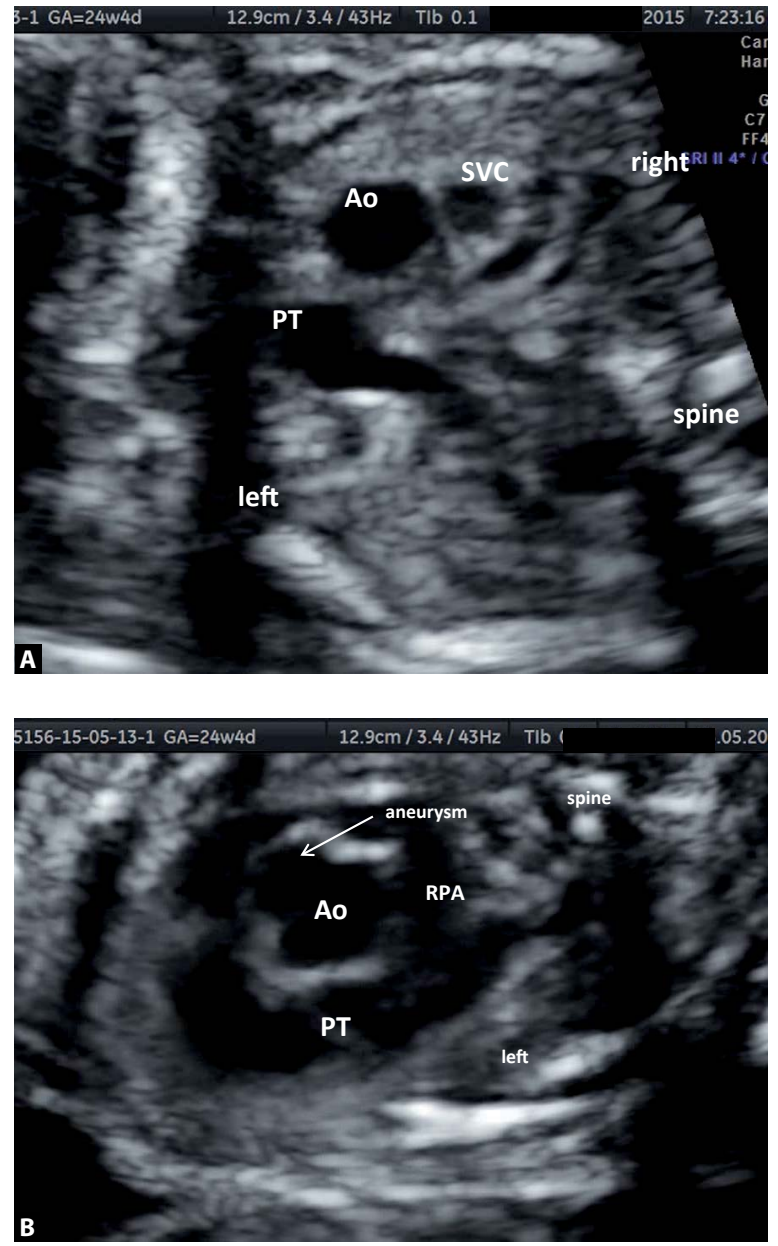

Figure 10. Upper mediastinum with an aneurysm of the ascending aorta in fetus with Marfan syndrome; A. Three-vessel view with dilatation of the aorta; B. Aneurysm of the ascending aorta; Ao - aorta; PT — pulmonary trunk; RPA — right pulmonary artery; SVC - superior vena cava

in the right-sided arch which also involves the right duct. As a result of this process, the left-sided aortic arch is formed [29]. If no regression occurs and both arches persist, DAA remains (Fig. 15).

From the anatomical point of view, the right aortic arch (RAA) is an anomaly in which the arch passes over the right instead of the left bronchus. In utero the visualization of the bronchus is difficult. The diagnosis of RAA is made on the basis of the course of the transverse aortic arch to the right of the trachea, which can be assessed in the upper mediastinum. Depending on the course of the DA in relation to the trachea we can distinguish two variants of the RAA. If the DA extends to the left and the aorta to the right of the trachea, then the vessels form a U shape (U sign) (Fig. 16). This variant is associated with aberrant left subclavian artery (ALSA), which forms a vascular ring. It could be isolated lesion, but cardiac anomalies have been reported in $10 \%$ to $50 \%$ of the cases $[29,30]$.
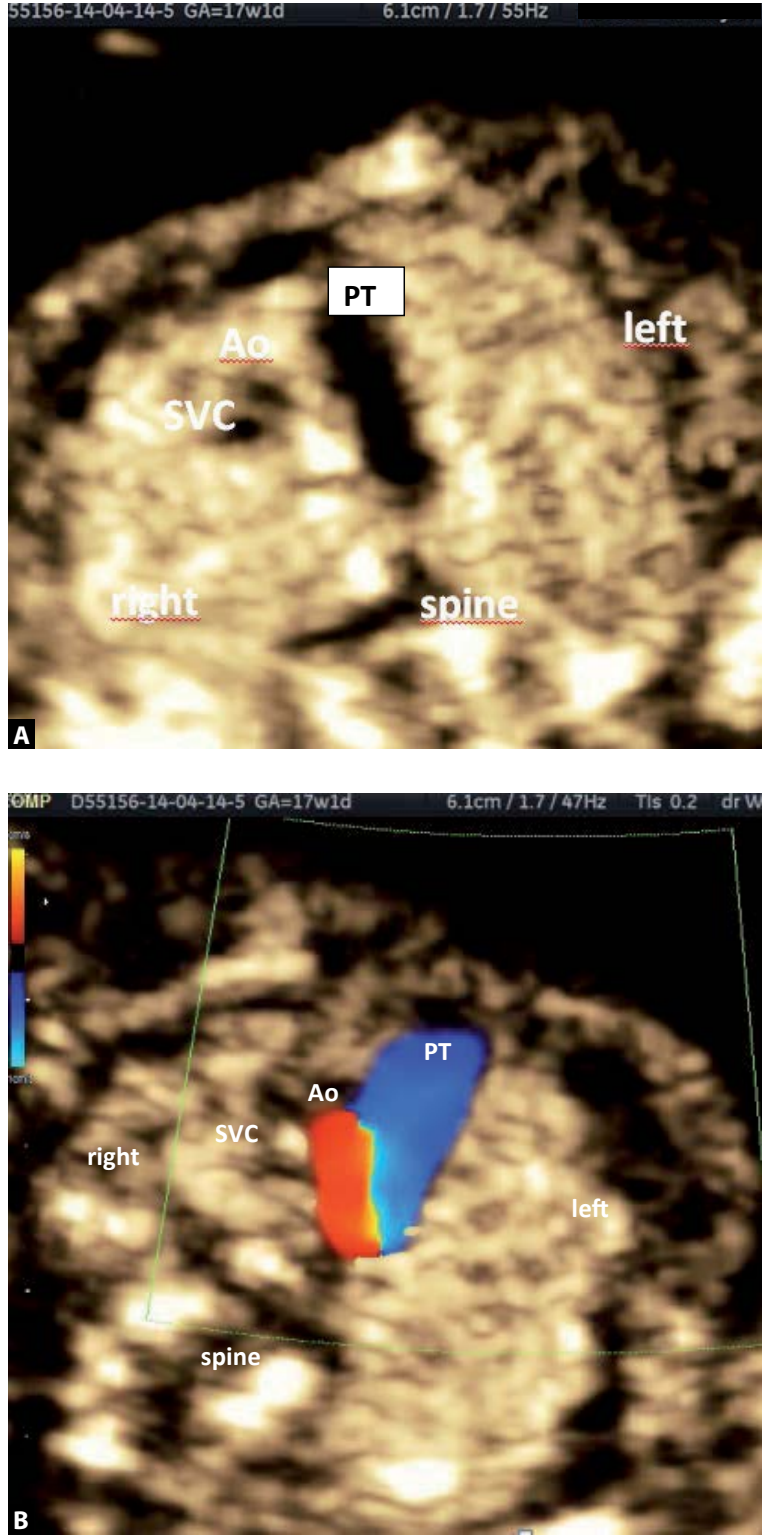

Figure 11. Upper mediastinum in hypoplastic left heart syndrome; A. Hypoplastic ascending aorta in 2D; B. A retrograde flow through a hypoplastic aortic arch; Ao - aorta; PT — pulmonary trunk; SVC - superior vena cava

The aorta and DA may lie to the right of the trachea, and then form a $V$ shape ( $V$ sign) (Fig. 17). In such cases they do not form a vascular ring. In this variant usually a mirror image of the branching vessel is observed, with the brachiocephalic trunk being the first vessel to depart, followed by the right common carotid artery and the right subclavian artery [30].

Another pathology detected in the upper mediastinum is the absence or hypoplasia of the pulmonary arteries or abnormal branching from the aorta. Pulmonary arteries can be dilated in cases of ductus arteriosus constriction and aneurysmal dilatation of the pulmonary arteries is found 


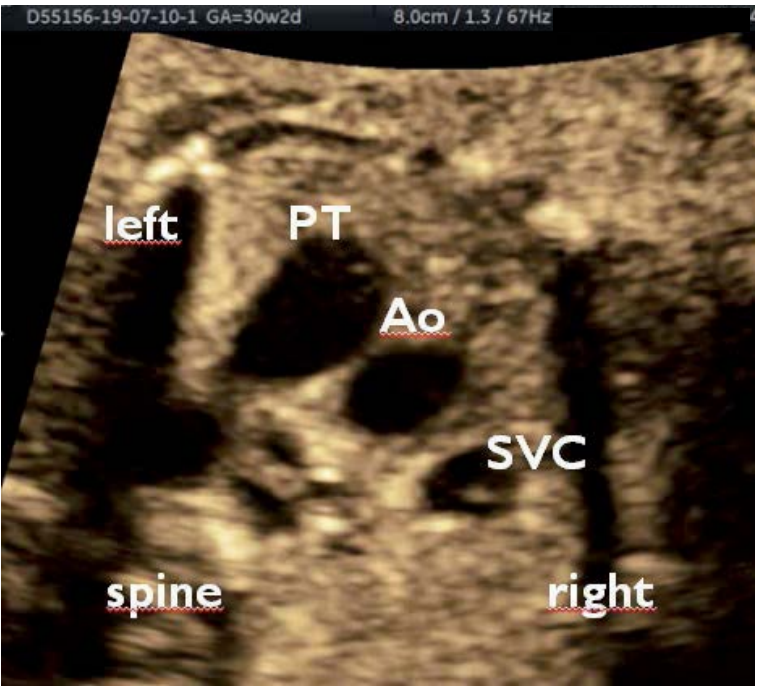

Figure 12. Abnormal vessel alignment in double outlet right ventricle. The left-to-right order is preserved, but the ascending aorta is shifted forward; Ao - aorta; PT — pulmonary trunk; SVC - superior vena cava

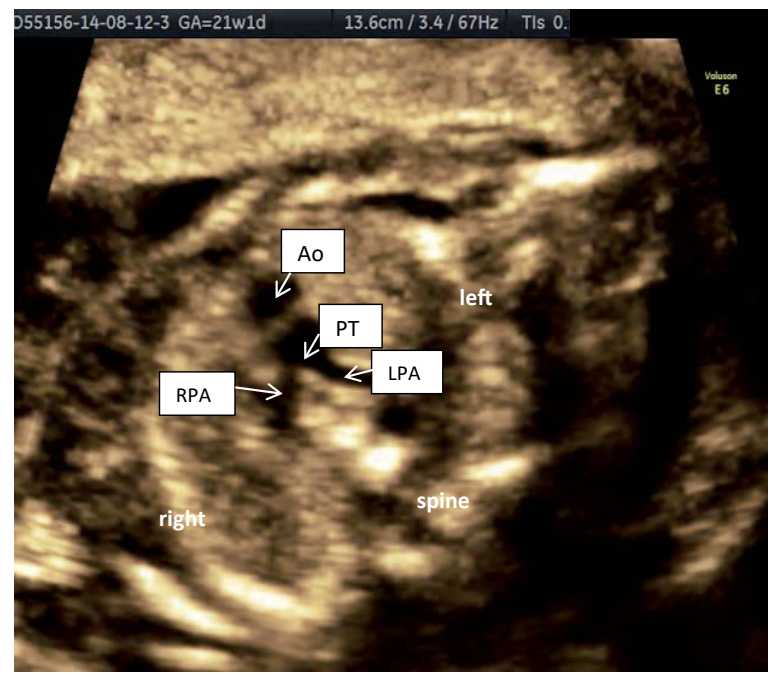

Figure 13. Abnormal vessel arrangement in transposition of the great arteries; vessels are arranged in a triangle shape; Ao - aorta; LPA — left pulmonary artery; PT — pulmonary trunk; RPA — right pulmonary artery

in tetralogy of Fallot, with absent pulmonary valve and ductus arteriosus. Variants of the standard view may be kinked, or the s-shaped ductal arch may become visible in late gestation.

\section{Abnormalities detected in color Doppler modality}

Cardiovascular defects detection rates can be increased by using the color Doppler modality. Color Doppler allows to detect stenosis, and absent or abnormal blood flow from the ductus arteriosus. The reversed flow in one of the arterial

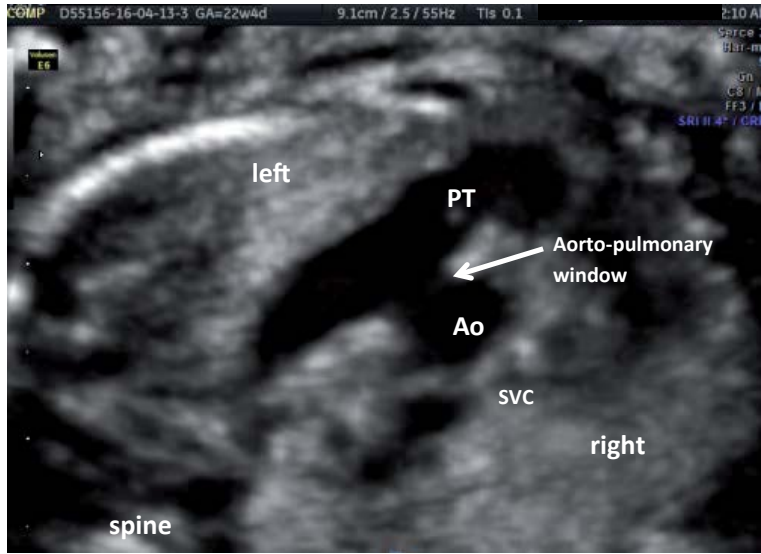

Figure 14. Upper mediastinum in a case of aorto-pulmonary window with interruption of the aortic arch: connection between aortic arch and pulmonary artery is visible. Absent thymus; in aCGH $22 q 11$ deletion confirmation; Ao - aorta; PT - pulmonary trunk; SVC - superior vena cava

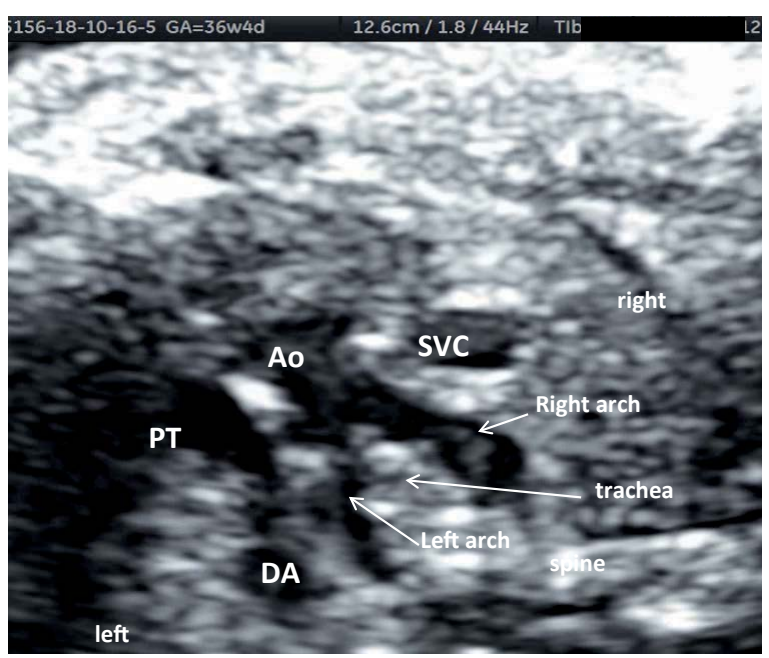

Figure 15. Double aortic arch; Ao — aorta; PT — pulmonary trunk; SVC - superior vena cava

vessels is a marker of ductal dependent heart defects and may be indicative of aortic atresia (Fig.11B), severe coarctation or interruption of the aortic arch or pulmonary atresia (Fig. 18). In turn, turbulent flow can be observed in 3VT view in cases of aortic stenosis and in fetuses with pulmonary stenosis. It is a result of increased velocity of the blood flow through a valve.

Color Doppler allows to detect an aberrant right subclavian artery (ARSA). ARSA, which presents as the last vessel extending from the aortic arch before the isthmus and running to the right, forward from the spine and behind the trachea and esophagus to the right arm, is present in nearly $1.5 \%$ of the population (Fig. 19) [26]. ARSA was found in over $20 \%$ of the fetuses with trisomy 21 and other chromosomal aberrations [31].Therefore, it was treated as a marker of aneuploidy, 


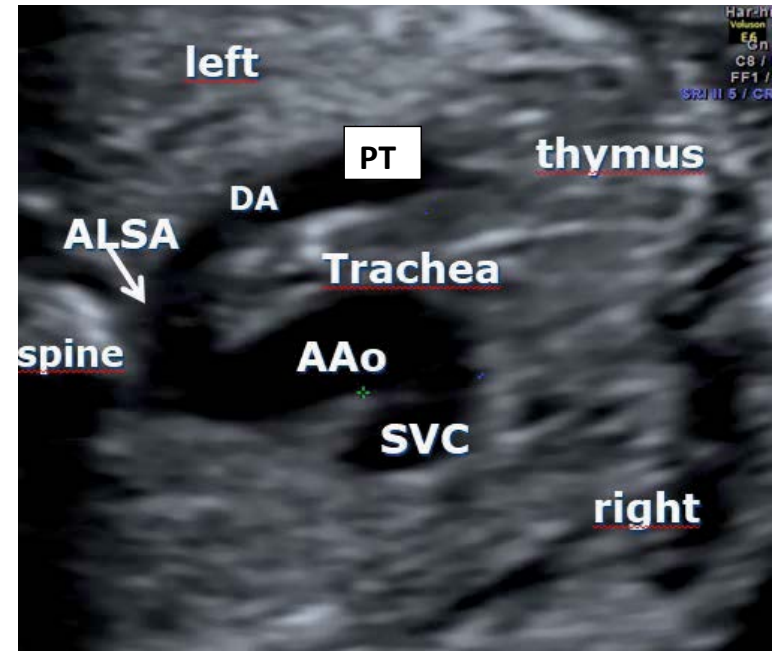

Figure 16. Three-vessel and tracheal view of the right aortic arch with aberrant left subclavian artery and left ductus arteriosus (the aortic arch forming U-shaped confluence with the ductus arteriosus); AAo — aortic arch; ALSA — aberrant left subclavian artery; DA — ductus arteriosus; PT — pulmonary trunk; SVC — superior vena cava

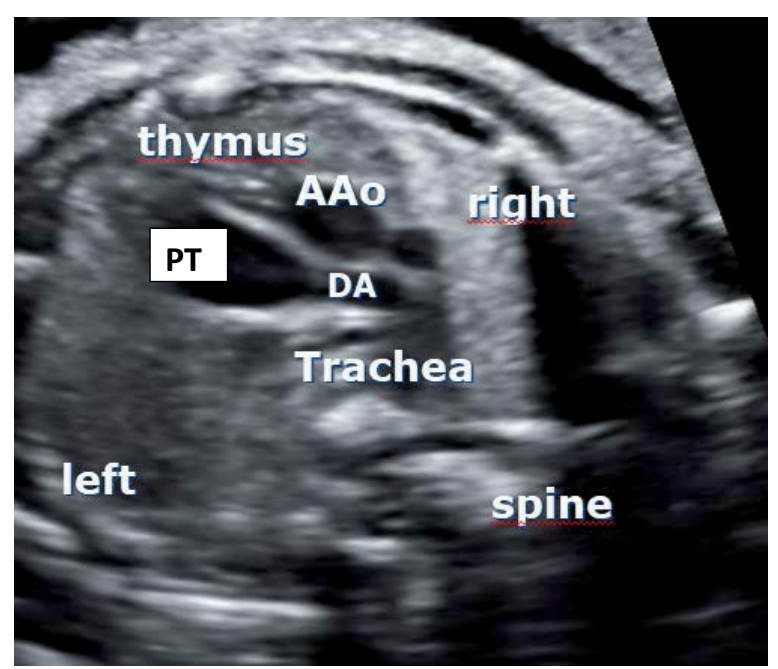

Figure 17. Three-vessel and tracheal view; right aortic arch with right ductus arteriosus (V-sign); AAo - aortic arch; DA — ductus arteriosus; PT — pulmonary trunk

increasing the risk by 10-fold [32]. However, the last study [33] showed that Down syndrome was present only in $0.4 \%$ of cases of isolated ARSA and authors concluded that isolated ARSA should be treated as a soft marker for Down syndrome.

\section{Thymus hypoplasia}

The thymus is the next organ which can be assessed in the upper mediastinum. The assessment of the thymus is important because thymic hypoplasia or agenesis (Fig. 9) is associated with the $22 q 11$ deletion and with conotruncal anomalies and anomalies of the aortic arch [24]. Thymic hypoplasia is also a common finding in cases of pre-term pre-labor

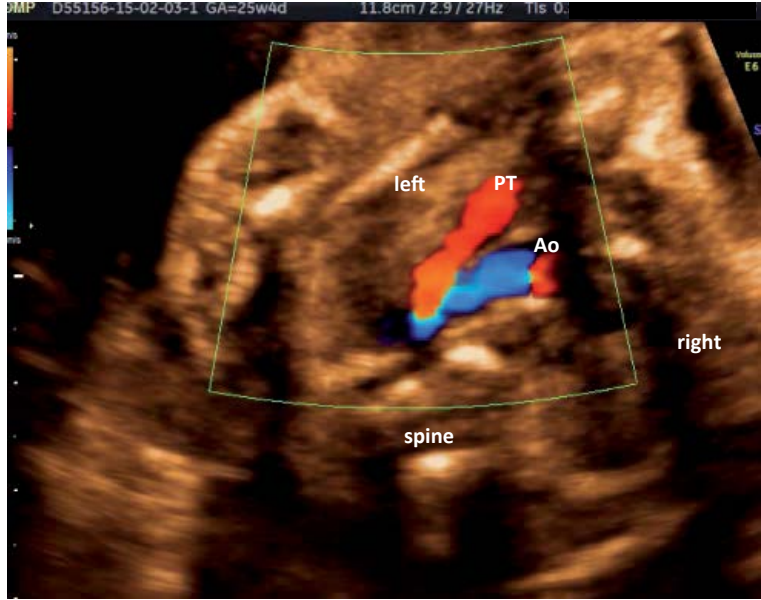

Figure 18. Reversed flow in pulmonary artery in case of pulmonary artery atresia; Ao — aorta; PT — pulmonary trunk

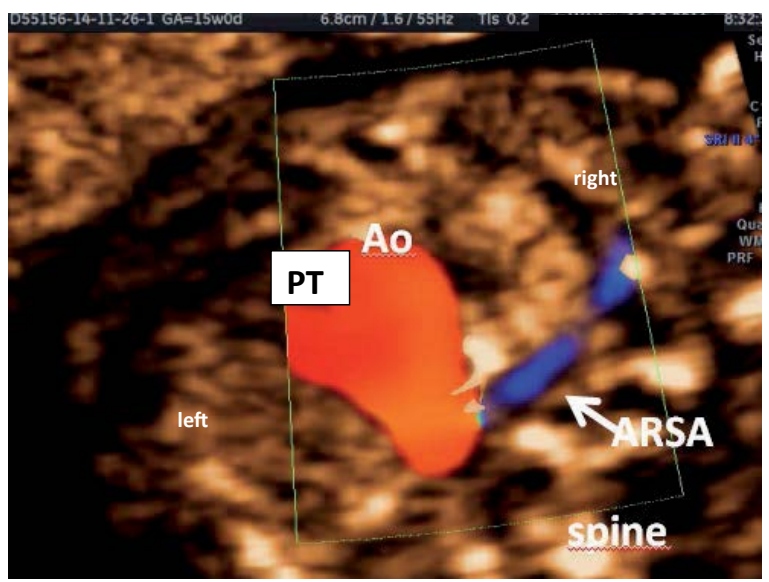

Figure 19. Three-vessel and tracheal view with aberrant right subclavian artery; Ao - aorta; ARSA - aberrant right subclavian artery; PT - pulmonary trunk

rupture of membranes, intrauterine growth restriction, maternal preeclampsia, and fetuses with Down syndrome and other aneuploidies. Thymic hypoplasia in those cases may be explained by the immune function impairment [34-36].

\section{CONCLUSION}

In summary, it should be emphasized that the abnormalities in the upper mediastinum may indicate the group of pathologies, but they do not allow to clearly determine the diagnosis. Only a comprehensive evaluation of the other planes as well as color and pulsed Doppler technique allow for a definite diagnosis. Nevertheless, the assessment of the 3VV and 3VT views increases the detection rate of fetal heart defects, especially in case of conotruncal and aortic arch anomalies. In addition, vascular and thymic abnormalities found in those planes signify the need to include genetic testing into the diagnostic process. 


\section{REFERENCES}

1. DeVore GR. The prenatal diagnosis of congenital heart disease--a practical approach for the fetal sonographer. J Clin Ultrasound. 1985; 13(4): 229-245, doi: 10.1002/jcu.1870130403, indexed in Pubmed: 3923046.

2. Allan LD, Crawford DC, Chita SK, et al. Prenatal screening for congenital heart disease. BMJ. 1986; 292(6537): 1717-1719, doi: 10.1136/bmj.292.6537.1717.

3. Copel JA, Pilu G, Green J, et al. Fetal echocardiographic screening for congenital heart disease: the importance of the four-chamber view. Am J Obstet Gynecol. 1987; 157(3): 648-655, doi: 10.1016/s00029378(87)80022-4, indexed in Pubmed: 3631166.

4. Sharland GK, Allan LD. Screening for congenital heart disease prenatally. Results of a 2 1/2-year study in the South East Thames Region. $\mathrm{Br}$ J Obstet Gynaecol. 1992; 99(3): 220-225, doi: 10.1111/j.1471-0528.1992. tb14503.x, indexed in Pubmed: 1606121.

5. Benacerraf BR. Sonographic detection of fetal anomalies of the aortic and pulmonary arteries: value of four-chamber view vs direct images. AJR Am J Roentgenol. 1994; 163(6): 1483-1489, doi: 10.2214/ajr.163.6.7992752, indexed in Pubmed: 7992752

6. Tegnander E, Eik-Nes SH, Johansen OJ, et al. Prenatal detection of heart defects at the routine fetal examination at 18 weeks in a non-selected population. Ultrasound Obstet Gynecol. 1995; 5(6): 372-380, doi: 10.1046/j.1469-0705.1995.05060372.x, indexed in Pubmed: 7552797.

7. Stoll $C$, Dott $B$, Alembik $Y$, et al. Evaluation and evolution during time of prenatal diagnosis of congenital heart diseases by routine fetal ultrasonographic examination. Ann Genet. 2002; 45(1): 21-27, doi: 10.1016/s0003-3995(02)01111-5, indexed in Pubmed: 11934386.

8. Friedberg MK, Silverman NH, Moon-Grady AJ, et al. Prenatal detection of congenital heart disease. J Pediatr. 2009; 155(1): 26-31, 31.e1, doi: 10.1016/j.jpeds.2009.01.050, indexed in Pubmed: 19394031.

9. Paladini $D$, Rustico $M$, Todros $T$, et al. Conotruncal anomalies in prenatal life. Ultrasound Obstet Gynecol. 1996; 8(4): 241-246, doi: 10.1046/j.146 9-0705.1996.08040241.x, indexed in Pubmed: 8916376.

10. Yoo SJ, Lee YH, Kim ES, et al. Three-vessel view of the fetal upper mediastinum: an easy means of detecting abnormalities of the ventricular outflow tracts and great arteries during obstetric screening. Ultrasound Obstet Gynecol. 1997; 9(3): 173-182, doi: 10.1046/j.1469-0705.1997.09 030173.x, indexed in Pubmed: 9165680.

11. Achiron R, Glaser J, Gelernter I, et al. Extended fetal echocardiographic examination in detection of cardiac malformations in low risk women. BMJ. 1992; 304: 671-4.

12. Yagel S, Cohen SM, Achiron R. Examination of the fetal heart by five short-axis views: a proposed screening method for comprehensive cardiac evaluation. Ultrasound Obstet Gynecol. 2001; 17(5): 367-369, doi: 10.1046/j.1469-0705.2001.00414.x, indexed in Pubmed: 11380958.

13. Yagel $S$, Arbel $R$, Anteby EY, et al. The three vessels and trachea view (3VT) in fetal cardiac scanning. Ultrasound Obstet Gynecol. 2002; 20(4): 340-345, doi: 10.1046/j.1469-0705.2002.00801.x, indexed in Pubmed: 12383314.

14. Viñals F, Heredia F, Giuliano A. The role of the three vessels and trachea view (3VT) in the diagnosis of congenital heart defects. Ultrasound Obstet Gynecol. 2003; 22(4): 358-367, doi: 10.1002/uog.882, indexed in Pubmed: 14528470.

15. Tongsong $T$, Tongprasert $F$, Srisupundit $K$, et al. The complete three-vessel view in prenatal detection of congenital heart defects. Prenat Diagn. 2010; 30(1): 23-29, doi: 10.1002/pd.2404, indexed in Pubmed: 19911415.

16. Carvalho JS, Allan LD, Chaoui R, et al. ISUOG Practice Guidelines (updated): sonographic screening examination of the fetal heart. Ultrasound Obstet Gynecol. 2013;41(3):348-359, doi: 10.1002/uog.12403, indexed in Pubmed: 23460196.

17. Donofrio MT, Moon-Grady AJ, Hornberger LK, et al. American Heart Association Adults With Congenital Heart Disease Joint Committee of the Council on Cardiovascular Disease in the Young and Council on Clinical Cardiology, Council on Cardiovascular Surgery and Anesthesia, and Council on Cardiovascular and Stroke Nursing. Diagnosis and treatment of fetal cardiac disease: a scientific statement from the American Heart Association. Circulation. 2014; 129(21): 2183-2242, doi: 10.1161/01. cir.0000437597.44550.5d, indexed in Pubmed: 24763516.
18. Słodki M, Respondek-Liberska M. [Proposal of screening fetal heart examination form granted by Polish Ministry of Health Program Kardio-Prenatal 2008]. Ginekol Pol. 2009; 80(6): 466-470, indexed in Pubmed: 19642607.

19. Sekcja Ultrasonografii Polskiego Towarzystwa Ginekologicznego. [Polish Gynecological Society--Ultrasound Section Guidelines on ultrasound screening in uncomplicated pregnancy (2 December 2011)]. Ginekol Pol. 2012; 83(4): 309-315, indexed in Pubmed: 22712266.

20. Rekomendacje Sekcji Ultrasonografii Polskiego Towarzystwa Ginekologicznego w zakresie przesiewowej diagnostyki ultrasonograficznej w ciąży o przebiegu prawidłowym - 2015 r. Ginekol Pol. 2015; 86: 551-559.

21. Wójtowicz A, Respondek-Liberska M, Słodki M, et al. The significance of a prenatal diagnosis of right aortic arch. Prenat Diagn. 2017; 37(4): 365-374, doi: 10.1002/pd.5020, indexed in Pubmed: 28177551.

22. Paladini $D$. How to identify the thymus in the fetus: the thy-box. Ultrasound Obstet Gynecol. 2011; 37(4): 488-492, doi: 10.1002/uog.8854, indexed in Pubmed: 20954168.

23. Cho JY, Min JY, Lee YH, et al. Diameter of the normal fetal thymus on ultrasound. Ultrasound Obstet Gynecol. 2007; 29(6): 634-638, doi: 10.1002/uog.3979, indexed in Pubmed: 17385216.

24. Chaoui R, Heling KS, Lopez AS, et al. The thymic-thoracic ratio in fetal heart defects: a simple way to identify fetuses at high risk for microdeletion 22q11. Ultrasound Obstet Gynecol. 2011; 37(4): 397-403, doi: 10.1002/uog.8952, indexed in Pubmed: 21308838.

25. Sinkovskaya E, Abuhamad A, Horton S, et al. Fetal left brachiocephalic vein in normal and abnormal conditions. Ultrasound Obstet Gynecol. 2012; 40(5): 542-548, doi: 10.1002/uog.11166, indexed in Pubmed: 22461379.

26. Chaoui R, Heling KS, Sarioglu N, et al. Aberrant right subclavian artery as a new cardiac sign in second- and third-trimester fetuses with Down syndrome. Am J Obstet Gynecol. 2005; 192(1): 257-263, doi: 10.1016/j. ajog.2004.06.080, indexed in Pubmed: 15672034.

27. Wójtowicz A, Ochrem D, Dobosz A, et al. Neonatal Marfan syndrome diagnosed prenatally. Ginekol Pol. 2017; 88(1):45, doi: 10.5603/GP.a2017.0009, indexed in Pubmed: 28157248

28. Kailin JA, Santos AB, Yilmaz Furtun B, et al. Isolated coarctation of the aorta in the fetus: A diagnostic challenge. Echocardiography. 2017; 34(12): 1768-1775, doi: 10.1111/echo.13578, indexed in Pubmed: 29287141.

29. Edwards J. Vascular rings and slings. In: Moller J. ed. Fetal, Neonatal, and Infant Cardiac Disease. Appleton \& Lange, Norwalk 1990: 745-754.

30. Achiron R, Rotstein Z, Heggesh J, et al. Anomalies of the fetal aortic arch: a novel sonographic approach to in-utero diagnosis. Ultrasound Obstet Gynecol. 2002; 20(6): 553-557, doi: 10.1046/j.1469-0705.2002.00850.x, indexed in Pubmed: 12493043.

31. Chaoui R, Thiel G, Heling KS. Prevalence of an aberrant right subclavian artery (ARSA) in fetuses with chromosomal aberrations. Ultrasound Obstet Gynecol. 2006; 28: 414.

32. Paladini $D$, Sglavo $G$, Pastore $G$, et al. Aberrant right subclavian artery: incidence and correlation with other markers of Down syndrome in second-trimester fetuses. Ultrasound Obstet Gynecol. 2012; 39(2): 191-195, doi: 10.1002/uog.10053, indexed in Pubmed: 21793087.

33. Sagi-Dain L, Singer A, Josefsberg $S$, et al. Microarray analysis has no additional value in fetal aberrant right subclavian artery: description of 268 pregnancies and systematic literature review. Ultrasound Obstet Gynecol. 2019; 53(6): 810-815, doi: 10.1002/uog.20208, indexed in Pubmed: 30584678.

34. Musilova I, Hornychova $\mathrm{H}$, Kostal M, et al. Ultrasound measurement of the transverse diameter of the fetal thymus in pregnancies complicated by the preterm prelabor rupture of membranes. J Clin Ultrasound. 2013; 41(5): 283-289, doi: 10.1002/jcu.22027, indexed in Pubmed: 23505029.

35. Cromi A, Ghezzi F, Raffaelli R, et al. Ultrasonographic measurement of thymus size in IUGR fetuses: a marker of the fetal immunoendocrine response to malnutrition. Ultrasound Obstet Gynecol. 2009; 33(4): 421-426, doi: 10.1002/uog.6320, indexed in Pubmed: 19306477.

36. Karl K, Heling KS, Lopez AS, et al. Thymic-thoracic ratio in fetuses with trisomy 21, 18 or 13. Ultrasound Obstet Gynecol. 2012; 40(4): 412-417, doi: $10.1002 /$ uog. 11068 . 